\title{
DIGRESSÕES SOBRE MEDIAÇÃO, CONSUMAÇÃO DE CONTRATO SOCIAL E A [IN]IMPORTÂNCIA DO CONFLITO
}

\author{
DIGRESIONS REGARDING MEDLATION, CONSUMPTION OF SOCIAL CONTRACT \\ AND THE [IN]CONSEQUENCE OF THE CONFLICT
}
DIGRESIONES RESPECTO A LA MEDLACIÓN, LA CONSUMACIÓN DEL CONTRATO SOCLAL Y LA IINTTRASCENDENCLA DEL CONFLICTO

\author{
por Diego Fernando Yanten Cabrera ${ }^{1}$ e Arnulfo Sánchez García ${ }^{2}$
}

\section{RESUMO}

A explicação genética da Lei, como criador "suposto", que permite legitimar suas regras legais como devidamente obedecidas, como resultado de um contrato original e universalmente predicado, possibilita - apesar do que está declarado atualmente -, o suposição, irrestrita, de que todos devem - e querem ou devem querer - estar em conformidade com as regras e, nesse fato, conjecturar a legitimidade da autoridade. No entanto, sim, por um momento, essa suposição é considerada como o produto de uma mentira de protocolo, embora necessária, a própria certeza, baseada na improbabilidade dessa suposição, não é legítimo que todos interpretem a lei, arbitrariamente, imposta? talvez o mediador ainda não tenha o direito de esmaecer o conflito, que é a mediação em si, interpretando o interpretativo? e, talvez, não seja exatamente a ausência de segurança jurídica a razão pela qual o conflito não é tal, mas uma consideração natural da lei, condicionada por sua própria constituição?

Palavras-chave: Interpretação; Mediação; Criação; Pacifismo; Direito

\begin{abstract}
The genetic explanation of Law, as a "supposed" creator that allows to legitimize its legal rules as duly obeyed, as a result of an original and universally predicated contract, allows - despite what is currently stated - the presupposition, unrestricted, that everyone must - and want or should want - to conform to the norms and, in that conforming fact, to assume the legitimacy of the authority. However, yes, for a moment, this assumption is considered as the product of a protocol mendacity, although necessary, the certainty itself lies in the improbability of this assumption, is it not legitimate for everyone to interpret the law, arbitrarily, imposed? The mediator is not already entitled to fade the conflict, which is the mediation itself, interpreting the interpretative?, and, perhaps, is not precisely the absence of legal certainty the reason why the conflict is not such, but a natural consideration of law, which is conditioned by its own constitution?
\end{abstract}

Keywords: Interpretation; Mediation; Creation; Pacifism; Law

\section{RESUMEN}

La explicitación genética del Derecho, como un «pre-supuesto» creador, que permite legitimar sus reglas jurídicas como debidamente obedecidas, en tanto, producto de un contrato originario y universalmente predicado, posibilita -a pesar de lo actualmente manifestado-, la suposición, irrestricta, que todos deben -y quieren o deben querer- conformarse a las normas y, en ese hecho conformador, conjeturar la legitimidad de la autoridad. Empero, sí, por de pronto, se considera esta suposición como producto de una mendacidad protocolar, aunque necesaria, la certeza misma, radicada en la improbabilidad de esta suposición, ¿no legítima a todos para interpretar la ley arbitrariamente impuesta? ¿acaso, no está el mediador ya legitimado para desvanecer el conflicto, del cual se trata la mediación misma, interpretando lo interpretativo? y, quizá, ¿no es, precisamente, la ausencia de certeza jurídica la razón por la que el conflicto no es tal, sino una consideración natural del Derecho, que se condiciona por su constitución propia?

Palabras clave: Interpretación; Mediación; Creación; Pacifismo; Derecho

\footnotetext{
1 Doctorante en Métodos Alternos de Solución de Conflictos de la Universidad Autónoma de Nuevo León (México). Profesor titular e investigador, adscrito al grupo de investigación GICPODERI, de la Universidad Santiago de Cali (Colombia). Docente de la Cátedra Historia del Derecho, vinculado a la Facultad de Derecho y Criminología (FACDYC) de la Universidad Autónoma de Nuevo León (UANL). Mail: diego.yanten00@usc. edu.co

2 Arnulfo Sánchez García es doctor en Derecho por la Universidad Rey Juan Carlos. Profesor Titular "A” tiempo completo de Derecho en la Universidad Autónoma de Nuevo León. Abogado. Investigador del Centro de Investigación de Tecnología Jurídica y Criminológica de la Facultad de Derecho y Criminología de la misma Universidad. Investigador Nacional Nivel I CONACYT (SNI-I). Mail: arnulfo.sanchezgrc@uanl.edu.mx
} 


\section{I PEDAGOGIA NO AMBIENTE PENITENCIÁRIO: A EDUCAÇÃO QUE TRANSFORMA COM EDUCAÇÃO NO AMBIENTE PENITENCIÁRIO \\ 1. INTRODUCCIÓN}

La revolución estructural de la dinámica social ha supuesto que la sociedad misma, ya no aislada en la no comprometida «alienación cultural y política» (Fisas, 2011, p. 5), se adentre, progresivamente, en la gestión de su propio entorno, adscribiendo constantemente una verdadera Cultura de Paz, la cual descrita teleológicamente, pretende «...alcanzar equilibrios dinámicos que supongan el máximo bienestar posible para los actores de cada realidad y de cada momento, e intentar que este equilibrio sea igualmente sostenible» (Muñoz \& Molina, 2010, p. 54), lográndose, en forma paulatina, la edificación -el redescubrimiento- de una idiosincracia pacífista que, además, no suponga esquemas unidireccionales, sino en rigor multifacéticos.

El emplazamiento «comprometido» de la sociedad, respecto de su peculiar sinergia, presupone -como resulta obvio-, más allá de un esquema aditivo, en el cual, sólo se trate de individuos agregados, una asignación hacia lo social que vea en los sujetos -sin que aquéllos extravíen propia identidad- un encuentro difuminado por un propósito comunitario preponderante, además de elementos configurativos - como se verá más adelante- e instituciones que avalen, como posible, el compromiso mismo con presupuestos potencializadores para coadyuvar un efectivo convenio socio-integrativo ingenierilmente constructivo, esto es, aquel que, por definición, interpreta lo social partiendo de la figuración de una nueva visión: esto implica, pues, que «... la comunidad debe verse como un agente moral concreto porque deben protegerse las prácticas sociales e intelectuales que tratan a la comunidad de esta forma...» (Dworkin, 2005, p. 140).

La probabilidad de esta confirmación cultural ulterior -partiendo de que, en el ahora, se trata de una otra cultura más arraigada a lo conflictual (Cabello, 2016, p. 145)-, supone ya un eje propulsor previo y, en cierto sentido, avasallante: la «ciudadanización de la justicia», esto es, la consolidación, socialmente legitimadora que impele a la propia sociedad a movilizarse para dar resolución a las desavenencias que en el pecualiar relacionarse de sus miembros puede -como efectivamente ocurreacaecer (Gorjón, 2015, p. 116). Este proyectarse comprometido representa, a resueltas, la adscripción generadora de una Cultura de Paz gestante, que advierte en la interrelación generatriz, una nueva forma de entender lo humano, esto es, una interpretación afincada en el principium unus pro omnibus, omnes pro uno (Dumas, 2008, p. 89).

Consecuencialmente, al menos en aparicencia, parece que este surgimiento socio-constructivo impele, explícitamente, a la conformación de un Derecho permisivista que en la actualidad permita el ejercicio -el reencuentro- del pacifismo social sin que, en efecto, éste transgreda aquél. De esta forma, la alternatividad a lo jurídico, en concordancia con aquel, supone, ya siempre -se trate de métodos autocompositivos o heterocompositivos-, vías para la construcción social de lo social, de allí que los MASC sean, primariamente, potencializadores para la concresión del «cambio de paradigma» requerido por la Cultura de Paz y, concomitantemente a ello, funcionalicen el contexto propicio para «... generar o regenerar confianza e inclusive lazos sociales y afectivos entre los miembros de la comunidad, transformando las relaciones interpersonales en base a estrategias que generan el diálogo pacífico y participativo» (Gorjón \& Sauseda, 2018, p. 551). 
Sin embargo, comprender, en sentido amplio, el empoderamiento social sobre su propio contexto, implica la interpretación de la juridicidad en una forma distinta a la que se hace y, por descuento, esta -la interpretación- denota, en efecto, una visión de la mediación tendiente a la integración, de entre todas sus características, del módelo constructivo de sociedad dinamizante de la Cultura de Paz.

Así, en las líneas subsiguientes, ha de advertirse que, pese a lo enunciado por los preceptos legales -los cuales, por descuento, resultarán inconcordantes-, la mediación no puede ser entendida como una supresión a la creación del Derecho mismo, sino, al contrario, la forma de concretar el Derecho mismo, esto es, el mediador no resulta ser una figura que, siendo imparcial, solo ejecute la ley, al contrario, en su imparcialidad -si acaso existe tal cosa-, convierte su actuar en legislación práctica.

De buen principio, la pretensión que condicionan las líneas configurantes de la siguiente reflexión, suponen la [I-1] explicación de la génesis del Derecho, en tanto presunción autolegitimante de la consideración teleológica de la mediacion misma, sin embargo, sin observarse en esta un más allá que una praesumptio misma; sí, acaso, la explicación resulta convincente, entonces, la condición misma de lo argumentado, presupondrá en sí, la [I-2] elucidación de la [in] trascendencia del conflicto, por considerarse, en el actual estado de cosas jurídicas verificable en un otro sentido, para, al finalizar, expresar [I-3] una transformación en la consideración misma del mediador, no como simple subordinado a la voluntad de las partes involucradas - mediados- mas sí como legislador involuntario.

\section{EL COMPROMISO SOCIAL PREVIO SOBRE EL QUE ES POSIBLE HABLAR DEL HOMBRE DE DERECHO Y LA MASIFICACIÓN DE UNA IDEA REPLICADORA}

Concebir que el Derecho ha de obedecerse y adscribir una respuesta para esto, más allá de una simple razón corroborante como, por ejemplo, «porque sí» o «porque así se hace»e, incluso, de un raciocionio circular como el expresado en la formula: «porque el Derecho mismo así lo predispone», constituye, un requerimiento ético y, en tanto que, indemostrable -no así su carácter práctico-social (Atienza, 2009, p. 15) ${ }^{3}$ - una presuposición. Suposición esta -aun por precisar- que, es menester, explicar estructuralmente. Prístinamente, ha de observarse que, el carácter significante de la praesumptio esquematiza una consideración contrafáctica aditiva (Leroy, Padilla, Munguía, Burgos, \& Morando, 2009, p. 386) ${ }^{4}$, esto es, la suposición de una ilusión no-verificable, un salto legitimante que expresa su

\footnotetext{
3 Lo que aquí se problematiza no es la necesariedad del Derecho mismo, al contrario, lo que entra en cuestión es la pregunta ¿qué hace que obedezcamos al Derecho como lo hacemos?, sin embargo, la respuesta, no es, sin embargo, práctica, más bien, resulta moral, pues, en efecto, el Derecho es obedecido, de allí que, el Derecho sea un "fenómeno omnipresente en nuestras sociedades" y que "prácticamente no hay ninguna relación social que no esté, o pueda llegar a estar, regulada jurídicamente".

4 De entre las posibles consideraciones contrafactuales, puede, considerarse con especial relevancia, aquellas que se desprenden de la siguiente caracterización expresada - por nuestro autor- en la siguiente consideración: "la estructura de los contrafácticos se refiere a si éstos se focalizan en la adición, sustracción o sustitución de un antecedente. Los contrafácticos con una estructura aditiva son aquellos que añaden antecedentes para reconstruir la realidad (e.g. "Si hubiera tenido un paraguas, no me hubiera mojado"). Mientras que los contrafácticos con una estructura sustractiva son aquellos que eliminan antecedentes (e.g. "Si no hubiera llovido hoy, no me hubiera mojado"). Finalmente, los contrafácticos con una estructura sustitutiva son aquellos donde una adición reemplaza a una sustracción (e.g. "Si hubiera ido al trabajo manejando en vez de caminando, no me hubiera mojado")".
} 


\section{I PEDAGOGIA NO AMBIENTE PENITENCIÁRIO: A EDUCAÇÃO QUE TRANSFORMA COM EDUCAÇÃO NO AMBIENTE PENITENCIÁRIO}

propia necesariedad en la conexión con un hecho gestante que, a sí mismo, requiere una explicación para su presencia, precisamente, porque esta yace inexplicada. De ese modo, la significación misma impele por un «sobre qué...», él cual es la razón para su nacimiento, un eje relacional entre un justificante [no-presente] que precisa su «para...» que, en definitiva, es la razón de la presunción misma.

Normalmente, a esta cuestión precede un incondicionado presente que no replica por su «¿qué...?», sino, porque lo que se define, de alguna u otra manera, requiere, en tanto pre-puesto a la definición misma, una condición legítima -entiéndase ético-configurativa- para su presencia. Luego, el enigma no se trata del «qué», ni cuanto menos del «por qué», al contrario, lo referente será siempre una razón moral de lo definido, aunque, este ya-presente no contenga en su génesis misma aquella razón. En ese sentido, lo no puesto en duda es el Derecho mismo, sensu contrario, lo dubitativo radica en la conexión entre normas impuestas y razones éticas para su obediencia, siendo estas últimas, las que, al parecer, se encuentran ausentes (Ross, 2008, pp. 201-202).

Aparentemente, este tipo de razonamiento superpuesto resulta, en cierto sentido, propiciado por el Derecho mismo, el cual, a su vez, abunda en explicitaciones de este tipo. Paradigmáticamente, una secuela que expresa similitud con el análisis antecedente, se advierte en la codificación teorética de la grundnorm (Kelsen, 2007, p. 201 \& ss.), que expresa un complemento para la validez jerárquica del Ordenamiento Jurídico que, abstraída, implicaría una de dos consecuencias: o bien, lo normativo queda inexplicado o bien, la producción normativa encuentra su límite en una regla que no tiene norma que la fundamente. Luego, la «norma fundante básica» es un presupuesto irreal para explicar lo que, efectivamente, hace su presencia: esto es, la constitución como norma generante de las reglas jurídicas, las cuales encuentran su fundamento, a su vez, en aquella y esta, a su vez, en lo supuesto -la grundnorm-, o sea la regla no corroborable, que es no explicitada por ninguna, salvo lo presupuesto por cierto e inciertamente pospuesto.

Considérese, además, un supuesto adicional, excesivamente popular entre los soft-positivistas, la rule of recognition que expresa, una suerte de convencionalismo inescrutado, aunque determinador, en la identificación de las reglas jurídicas (Hart, 1961, p. 125 \& ss.), según el cual, características lingüísticas no-observables, aunque verificables, pululan en las reglas y, por una suerte, de lenguaje privativo, propio de los jurístas, las reglas de derecho difieren en su constitución característica de las demás normas similares, e. g. las ético-morales, lo que posibilita su identificación, la cual, a su vez, permite, en efecto, concebir [no-indiscriminadamente] una peculiaridad propia en las normas jurídicas que, a su vez, condicionan el todo del Derecho.

De esa manera preponderar en la explicitación del Derecho como un algo no necesariamente verdadero, parece no atentar contra la tradición jurídica, sino, corroborarla. Consecuentemente, si ha de superarse el cuestionamiento superpuesto al enigma: ¿puede el Derecho, realmente, contener una explicación legítima para expresar la obligatoriedad de las normas jurídicas?, el presuponer parece la vía indicada para dar una respuesta adicional a aquellas que yacen como insuficientes, en tanto que, emergen de diversas concepciones contemplativas (Finnis, 1992, pp. 391-392) que hacen, sin más, de la obligatio, así impuesta, un condicionamiento eticista inexpugnable, empero, científicamente, inescrutable, esto es, una creencia elegantemente expresada, no obstante, carente 
de verificación. Ciertamente, el Derecho está presente, aunque la explicación «legítima» para la ordenación del monopolio coercitivo que condiciona las acciones humanas -verdaderamente lo hace-, resulta injustificada ab initio.

Aparentemente, la explicitación legítimo-genética del Derecho escapa a toda contemplación pacífica (Peces-Barba, 2000, pp. 14-15), sin embargo, ¿acaso, esto mismo, expresa su no sustancialidad, su ausencia de importancia, la insignificancia misma de una respuesta no requerida más que por la recalcitrancia de los moralistas? En modo alguno, precisamente, advertir la praesumptio, en su verdadera significación, permite comprender situaciones malinterpretadas del ahora -para el caso presente, el papel del mediador-. Si se considera, formalmente, la vida -por decirlo de alguna manera- de la presunción, empero, esta carecer de comprobación posible, la mendacidad ocupa el lugar de la facticidad, esto es, la falsedad del juicio se hace ostensible en cuanto mentira, una no-verdad, sin embargo, permite, pese a su obvio «desperfecto», expresar una configuración ostensible.

Que el Derecho pueda explicarse en su nacimiento implica, necesariamente, una creencia, una portentosa fe -en sentido, eminentemente, bíblico, o sea, el ser «... la certeza de lo que se espera, la convicción de lo que no se ve...» (He. 11, 1) - que ocupa el lugar de lo históricamente acaecido -en tanto, incomprobable-, sensu contrario, lo inexplicado yace velado y la ausencia de explicitación supone, pues, una inconformidad por lo normado; en definitiva, subyace la posibilidad del «iqué obliga a obedecer x o y regla?», si éstas surgen del arbitrio de un otro -con iguales características a quien interroga, un, en definitiva, nada más que ser humano-, que no fue legitimado, en un origen ético-gestante, para confeccionarlas.

Luego, parece aquí encontrarse la realización característica de la presunción, la evitación de un hecho, concomitante e indeseado, que por su naturaleza es evitable al precio de la verdad. La rudeza de este argumento se compensa con el carácter perogrullezco que encierra, pues, no puede darse por, efectivamente, acaecido aquello que no puede, en modo alguno, probarse, la pre-suposición implica eso hasta que el hecho presupuesto sea descubierto como realizado-históricamente. En tanto, la condición $R$ que supone la presencia legítima de $S$, no sea vislumbrada de las sombras, $R$ seguira siendo un supuesto incomprobable, aunque $S$, efectivamente, se obedezca (Austin, 1995, p. $24)^{5}$. Ergo, no es necesario $\operatorname{Ra} S$ para que $S$ se encuentre presente, sin embargo, es necesario $R$ para que $S$ siga reproduciéndose, al menos, éticamente. La legitimación que $R$ expresa en $S$, permite a $S$ subsistir frente a quien opte por un carácter dubitativo con respecto a $S$, en tanto al «ipor qué ha de obedecerse a $S$ ?» si, acaso, el enigma carece de respuesta creible $R$, por lo tanto, $R$ es increible, pero, necesaria en un sentido, el ético, no, así, el práctico.

No obstante, carece de fundamento suponer que $S$ requiere de $R$ para ejercer su orden coercitivo

\footnotetext{
5 Sensu contrario, al carecer, el Derecho, de explicitación ético-justificativa, no por eso deja de ser obedecido. Suele considerarse que, primariamente, el miedo al mal que deviene, en la sanción misma, impele al hombre a actuar conforme a la regla que determina, con anterioridad, su comportamiento. Así Austin, precisaba, con claridad: «I am determined or inclined to comply with the wish of another, by the fear of disadvantage or evil. I am also deter- mined or inclined to comply with the wish of another, by the hope of advantage or good. But it is only by the chance of incurring evil, that I am bound or obliged to compliance. It is only by conditional evil, that duties are sanctioned or enforced. It is the power and the purpose of inflicting eventual evil, and not the power and the purpose of imparting eventual good, which gives to the expression of a wish the name of a command».
} 


\section{I PEDAGOGIA NO AMBIENTE PENITENCIÁRIO: A EDUCAÇÃO QUE TRANSFORMA COM EDUCAÇÃO NO AMBIENTE PENITENCIÁRIO}

adecuadamente (Beling, 2002, p. 41) ${ }^{6}, S$ no necesita de R, su solicitud viene precedido por la pregunta que requiere a $R$, luego, sin que se haga efectivo el enigma sobre la legitimidad ético-originaria de $S$, $R$ no es aprehensible, esto es, se requiere dudar de la legitimidad genética de $S$, aunque, actualmente, se obedezcan sus reglas, para que $R$ explique porqué, efectivamente, deben obedecerse. Tal es el carácter restrictivo y cuasi-explicativo de la presunción [R] (Hobbes, 1980, pp. 136-137)7.

Si ha de pre-suponerse, contraintuitivamente, que el Ordenamiento Jurídico posee una explicación que supone su debida obediencia y que expresa, a su vez, que quien desobedece debío actuar conforme a lo desobedecido (Alchourrón \& Buligin, 1997, p. 25), entonces, elemental resulta el argumento democrático-configurativo, esto es, aquel vertido en las clausulas del Social Contract, según el cual, «... sucediendo la voz del deber al impulso físico y el derecho al apetito, el hombre, que antes no había considerado ni tenido en cuenta más que su persona, se ve obligado a obrar basado en distintos principios, consultando a la razón antes de prestar oído a sus inclinaciones...» (Rousseau, 1983, p. 47).

Mas, en la elucidación del hombre, condicionado por un constante distanciarse respecto de su desangelada configuración arcaíco-primitiva, la suposición misma que conduce al hombre social, expresa una versión de aquel -el hombre- que contradice su otra condición: el constituirse ya, por ser quien es, como pacifista. En cierto sentido, esta presuposición fracasa, pues, si bien considera, igualmente, que, el estadio prejurídico implica, a su vez, en el individuo, «el estado de perfecta libertad para ordenar sus acciones y disponer de sus posesiones y personas como juzguen adecuado, dentro de los límites de la ley de la naturaleza, sin pedir permiso ni depender de la voluntad de otro hombre» (Locke, 2005, p. 17), al predisponer, al sujeto como arbitrario, pasa por alto que, si bien, todo le es posible, menos, lo cual constituye una idea replicadora -incluso para quien no suscribe lo aquí precisado, empero, sujeta la explicación de esto a otra razón-, atentar contra un otro que es igual a él. Este estado natural, en su significación inmediata, es un estado de paz, subsecuente, a la igualdad, autoevidente, entre los hombres que pueblan el mundo.

No obstante, dado que es imposible la no transgresión, incluso en este Estado natural del hombre que, por su condición, tiende al pacifismo en tanto que inherente a su situación, la justificación misma del Derecho parte, de la, igualmente, imposible autoregulación de este -el Estado natural- por los hombres en libertad y, en ese sentido, presupuestamente válida, surge la necesariedad evidente del Contrato Social aglutinante de una única condición social protectora, esta es, la ley natural misma que expresa, en tanto índole inmanente del hombre -y obligación misma- (Locke, 2009, p. 90), la

\footnotetext{
6 El argumento de la pretensión punitiva -por contra a lo aquí expresado- expresa una pre-suposición circular, en la cual, el Derecho expresa, en un doble sentido, lo que el Derecho mismo propone: «Derecho Penal en sentido punitivo jus puniendi, es la relación jurídica fundada en el Derecho Penal en sentido objetivo, por medio de la cual un determinado sujeto de derecho tiene el derecho de que el delincuente sufra pena; éste es, pues 'punible', tiene un deber de sometimiento penal».

7 Tal parece ser el sentido que brinda Hobbes, precisamente, a la presunción, al cuestionarse sobre la concurrencia de pasado y futuro que de ella sobrevienen: «Así como la prudencia es una presunción del futuro derivada de la experiencia del pasado, así también existe una presunción de cosas pasadas extraídas de otras cosas pasadas también. Pues quien ha visto porqué caminos o graduaciones ha llegado un Estado floreciente a caer primero en la guerra civil y luego en la ruina, deducirá viendo las ruinas de cualquier otro Estado una guerra semejante, y que allí se han producido trayectorias similares. Pero esta conjetura tiene casi la misma falta de seguridad que la conjetura del futuro; ambas están basadas exclusivamente sobre la experiencia».
} 
paz y que, por descuento, garantiza la ulterioridad efectiva de la ya mentada ley. Entonces, el Derecho queda justificado ab origine, no por menester de un hombre incontrolable en sí, pues ya, regido por la ley natural misma, que aquilata su condición humana, entiende, ab initio, que su semejanza al otro le hace respetarlo y considerarse, a sí, en tanto comprometido. Surge así, entonces, desde la condición humana misma -no desde el Derecho- el homo pacis y, con él, el divino derecho para proteger el Estado mismo así descrito.

El homo pacis constituye la virtud ínnata al hombre, la supresión de una consideración innatural que menoscaba su linaje y lo expresa ajeno a la paz, y ésta, a su vez, constituye la razón del Derecho mismo, no como un sagrado profesar provechoso, sino, como una naturaleza que no puede pasarse por alto, sin destruir la razón humana misma. Ciertamente, el Derecho puede constituirse en razón para su propia existencia -lo cual es ya, ilógico-, sin embargo, «bien se puede, por interés y también por convicción, proclamar como sagrado aquello que, una vez pisoteado y profanado, trae por consecuencia que uno mismo ya no pueda sentirse a salvo y seguro» (Locke, 1999, p. 44), empero, tales reglas morales, se edifican sobre el fango fragoso momentaneo de lo inexplicado, si, acaso, no existe la «intangibilidad» (Gorjón \& Sáenz, 2013, p. 151) propicia que, en tanto, beneficio, funda las almas hacia una venidera fortuna socio-integrativa, en el antes y el despues, esto es, «el activo de paz».

Con todo, no ha de olvidarse, jamás, que la praesumptio, entendida como lo que es, expresa una suerte de predisposición ambiciosa para la comprehensibilidad de un hecho que, a resueltas, no puede ser comprobado, precisamente, por contenerse en un razonamiento contrafáctico aditivo. A pesar de esta obviedad gestante, en definitiva, todo se trata de un hermoso autoengaño que $-y$ aquí logra, en efecto, su verdadera fuerza significativa- explicita más que una verdad in-manifiesta, si acaso, se imbuye de ello la realidad aconteciente que, por no adscribirse bajo este supuesto, se difumina en miramientos espurios y condicionamientos circulares que explican la cosa por la cosa misma. Finalmente, ha de concederse que la autologicidad propia de la mendacidad, adscrita como eje originante de la asignación significante de la praesumptio, se expresa en la siguiente constatación: «... ¿qué es una bella mentira? Pues, sencillamente, la que posee su evidencia en sí misma...» (Wilde, 1986, p. 104).

\section{LA TRASCENDENCIA DE LO CONFLICTUAL O LA CONDICIÓN PREVIA DEL ANTAGONISMO: UNA POSIBILIDAD PARA LA EDIFICACIÓN DE UNA SOCIEDAD CONSTRUCTIVA YA PRESENTE}

Toda explicitación ética correspondiente a la obediencia legítima del Derecho -en el cual sea, realmente, aprehensible el Homo Pacis como naturaleza inmanente al hombre- adquiere resonancia en la construcción presuntiva del Contrato Social, entendido este, como un compromiso adscrito a un «sistema de cooperación social» que gesta un proposito teleológico-comunitario direccionado a la conservación de las normas, así pensadas, justas, lo cual, adquiere significatividad, pues, entre quienes así actuan «... tienden a desarrollarse lazos de amistad y de confianza mutua, lo que les une al esquema cada vez más sólidamente» (Rawls, 1995, p. 425), generándose, de esta forma, una doble posibilidad: la de «ser socios en el autogobierno»y, a su vez, aquella consistente en desterrar 


\section{I PEDAGOGIA NO AMBIENTE PENITENCIÁRIO: A EDUCAÇÃO QUE TRANSFORMA COM EDUCAÇÃO NO AMBIENTE PENITENCIÁRIO}

la práctica, eminentemente, actual en la cual «nuestra política es más bien una forma de guerra» (Dworkin, 2008, p. 15), lo que, en definitiva, a ultranza, permitirá inscribir en el individuo el axioma que reza: «... vos podeís hacer a otros algo que fácilmente sería escrito en el libro de la eternidad, ya sea el que se ve en la tierra, ya el otro que se cree en el cielo, habida cuenta de que cuanto recibis de los demás es testimonio de la virtud ajena, pero lo que haceís a los demás es signo e indicio expreso de la vuestra» (Bruno, 1981, p. 60).

Este Contractus Socialis, sin embargo, en tanto que irreal, supone una mendacidad -lo cual contraviene su propio sentido- creíble, empero, que coadyuva a la norma para ser obedecida, bajo el entendido de representar un, verdadero, mandato ético y no, simplemente, como el subproducto derivado de la fuerza, ciertamente, constituida en forma legítima y supuesta en la especificidad de un tiempo. Entonces, ha de comprehenderse que la vinculación a la regla de Derecho misma, no sólo acontece por la disposición de lo actual, sino que, la tradición, aunque pre-supuesta, establece un contenido legitimador que, no siendo proveniente de su propia naturaleza, se instala, allí, fuera, precisamente, en el objeto de su regulación: la sociedad, comprendida, de todo a todo, en tanto «sistema equitativo de cooperación social» (Rawls, 2002, p. 28) ${ }^{8}$. Que a esto, pueda anteponerse como objeción el hecho de que una mentira no podría justificar una institución, olvida esa misma postura que, «no tenemos de la verdad y el bien sino una parte y mezclada con el mal y la falsedad» (Pascal, 1999, p. 197), con lo cual, el argumento aquí yuxtapuesto queda salvaguardado en el carácter dubitativo de lo verdadero mismo.

Este es el contexto, en el cuál adquiere plausibilidad la aprehensión -ciertamente, apenas, bosquejada- de una sociedad constructiva, en el sentido, de esencialmente comprometida consigo misma, esto es, bajo la significación de la «ciudadanización de la justicia». Empero, esa doble vinculación de la sociedad al Derecho -se recordará, como elemento de genealógica legitimación de éste y esta como producto mismo de la regulación que éste ejerce-, expresa, además, la posibilidad misma de comprenderse desde lo jurídico, lo cual significa, no sólo encontrarse, en tanto, coparticipe de sus acertos, sino, además, participar de las irregularidades que la misma regla jurídica predispone (Frank, 2001, p. 25) ${ }^{9}$ por su propia constitución. Es en este sentido, derivado en efecto, de la constatación contractual presupuesta, en que puede entenderse cómo resulta posible que el mediador, mediando, cree derecho en una forma -no precisada todavía- especial.

La mediación en su devenir conceptual, tradicionalmente, suele considerarse «un procedimiento no adversarial en el que un tercero neutral, que no tiene poder sobre las partes, ayuda a estas a que en forma cooperativa encuentren el punto de armonía en el conflicto» (Gorjón \& Sánchez, 2015, p.

\footnotetext{
8 La sociedad, aprehendida en tanto sistema equitativo de cooperación social, implica, necesariamente, la concurrencia de dos fundamentales esquemas, para su aprehensión teorética: «...la idea de los ciudadanos (los que participan en la cooperación) como personas libres e iguales... y la idea de sociedad bien ordenada, esto es, de una sociedad efectivamente regulada por una concepción pública de la justicia».

9 Es, verdaderamente, ilustrativa la consideración -sobre todo en el contexto de esta investigación-, del compromiso socio-integrativo que se evidencia desde el individuo actuante: «Cuando, en cualquier área que afecta directametne a seres humanos, existe un grave problema no resuelto, la ausencia de solución es causa de mucos resultados calamitosos. Pueden ser considerados moralmente irresponsables, quienes, conscientes del problema, tratan de ocultarlo o de restarle importancia. ¿Por qué? Porque favorecen la creación de un estado de ánimo complaciente con los resultados calamitosos y poque tal complacencia impide esfuerzos que podrían, al menos parcialmente, servir para resolver un problema».
} 
16), denotando, de esta forma, al conflicto en tanto sustrato gestante de la mediación misma, la cual, se despliega -como los restantes MASC- intentando su transformación (Gorjón \& Steele, 2008, p. 6) y, en su proyección, constituyen ya una parte visible de la Cultura de Paz. Esta afirmación es, singularmente, notable en afirmaciones como aquellas que advierten en la mediación un «movimiento social» que, en su proyección «atiende a los interés subyacentes de las partes y concilia con los interés superiores de la sociedad en general, como modelo de producción del estado» (Gorjón, 2016, p. 14), con lo cual, la mediación no sólo expresa su condición de potencializadora de la integralidad, sino que, además, expresa una condición de pertenencia al Derecho.

La mediación, así, potencializa, en cuanto propulsora del redescubrimiento de la Cultura de Paz - extraviada en el enrevesado flujo de la no comprometida actualidad-, la vinculación del ciudadano que, en su actividad, superpone a su propio interés beneficios proyectivos -intangibles- que sobrepasan la trascendencia individual, precisamente, por el componente constructivo-social que ve, en la sociedad, no sólo un dirigir teleológico, sino, al contrario, un dirigirse juntos hacia la consecución de un ideal que, reencontrado, fluye como un beneficio para todos y la más noble determinación hacia la humanidad entera. Este reflujo constitutivo, cifrado entre Derecho y mediación (mediada por la sociedad constructiva), supone, un eje que construyendo refuerza las normas jurídicas como mandatos ético-obligatorios, precisamente, porque el ciudadano ve, en el Derecho, la forma cómo ha de protegerse su más innato y propio homo pacis, redescubierto por su compromiso, y lo justifica, día a día, con la generación más próxima y siempre presente: la paz como intangible. De esto se sigue que, «no hay mejor medio para conservar una ciudad acostumbrada a vivir libre que contar con sus ciudadanos» (Maquiavelo, 2002, p. 23).

Sin embargo, la comprensión del conflicto como epicentro de la mediación misma, pasa por alto, la naturaleza del paralelismo antagónico que este representa y al asignar, de esta forma, una fuerza constitutiva en el conflicto cifrada en la ulterioridad, esto es, codificar la concreción misma de la Cultura de Paz en «utilizar la energía del conflicto para propósitos más constructivos» (Galtung, 1998, p. 13), se oblitera la oportunidad de ver en el ser humano, la posibilidad de un profundo redescubrimiento de su tradición antecedente más notoria: el Homo Pacis mismo y el pacífismo como condición inmanente a tal condición humana. Así, si ha de suponerse que la sociedad contiene como eje nuclear a la paz -no como algo reñido con lo que el hombre representa, sino como algo por descubrir en él-, en tanto legitimante, asimisma, del Derecho, le corresponde un papel ciudadanizador en la prosecución de la aplicabilidad de normas, con lo cual denota, efectivamente, su carácter constructivista. De esa forma, el conflicto no sólo posee una resonancia, condicionada por la propia condición humana, en el sentido de entreverse en ella la paz misma como condición de su estado natural, sino que, permite, en su forma transformativa redescubrirse constantamente esta condición a cada paso, con cada nuevo compromiso, pues, en efecto, funciona como fuerza progresiva (Redorta, 2011, p. 23) y constitución integral de la sociedad como un todo.

Lo manifestado, no obstante, no expresa la plenitud del conflicto mismo, desde su función constructiva, como aspecto integrativo que permite redescubrir la fe perdida en la humanidad misma, no como potencia comunitaria tendiente a un nivel superior, empero, como descubrimiento de 


\section{0 | PEDAGOGIA NO AMBIENTE PENITENCIÁRIO: A EDUCAÇÃO QUE TRANSFORMA COM EDUCAÇÃO NO AMBIENTE PENITENCIÁRIO}

una olvidada naturaleza que el Derecho, en su nivel originario, intento proteger y que, hoy, aunque extraviado, lo sigue haciendo. Solo entonces, cuando se redescubra este significado oculto del conflicto, puede, realmente, considerarse, en tanto posible, la materialización de la ciudadanización de la justicia y la potencia concretivo-creadora de, verdaderas, reglas jurídicas en la mediación misma. Esta visión, ciertamente, añadida a las convencionales -conflicto como oportunidad y redescubrimiento de lo humano-, permite advertir, en efecto, una suerte de [in]trascendencia en el conflicto que, específicada, lo revela como importante para el impulso hacia la condición humana de la cual, al parecer, hemos sido expulsados.

En efecto, si el conflicto, en tanto, eficiente, esto es, propulsor de verdaderas relaciones sociales fundadas en el antagonismo y el desencuentro es - como se supone aquí- «[in]trascendente», habrá primero que precisar, porque la vinculación inicial, fundada en la fuerza transformadora del conflicto mismo se opone y, en cierto sentido, descamina el efecto revelador de la mediación misma: el efecto constructivo consustancial a la ciudadanización de la justicia. Desde luego, la conceptualidad asignada a este nuevo término, expresa, el porqué la visión mayoritaría, en cierto sentido, hace de la mediación -desde la perspectiva tradicional- un concepto descriptivo, parcialmente, verdadero. El nombre femenino antepuesto al conflicto, específicado, en el término «[in]trascendencia», no obtiene su significatividad característica de la supresión del conflicto como elemento de importante valor, pues, lo considera necesario para la conformación de la sociedad constructiva derivada del aprehender una, creciente, Cultura de Paz, lo que expresa es la condición de subproducto de un efecto -en espera de explicitación- que precede en el tiempo a éste. Si tal conclusión es verdadera, entonces, el producto ha de ser precisado en el esquema que permite que la mediación pueda ser desarrollada, esto es, el Derecho.

Consecuencialmente, cabría instituir los siguientes interrogantes: ¿cuál es el elemento, perteneciente al Derecho -o connatural a este mismo-, del cual procede el conflicto?, en ese sentido, ¿porqué este hace de aquél una figura [in]trascedente, es decir, derivado y subsecuencial, aunque, efectivamente, presente? Que la razón de la mediación sea, teleológicamente, la transformación del conflicto es indudable, sin embargo, de ¿dónde viene el conflicto mismo al interior del maremagnum normativo que hoy todo lo fusiona con una regla determinadora? Ciertamente, no de la ausencia de directriz normativa para un caso concreto, sino, mejor, de la condición implicita en la regla misma, esto es, la «textura abierta» (Raz, 1985, p. 99), la que a su vez, insuflando en el Derecho la incertidumbre que expulsa la posibilidad de encontrar un único sentido a cada regla jurídica (Alexy, 2006, pp. 7-9), expresa un antagonismo respecto a quién, en una circunstancia particular, tiene el derecho, la obligación o la garantía.

\section{LA MEDIACIÓN COMO ESQUEMA SOCIO-INTEGRATIVO QUE COMPRIME LA REALIZACIÓN DE UNA CONCRECIÓN CREADORA DEL DERECHO POSPUESTA A LA DISOLUCIÓN DEL CONFLICTO}

La Mediación como, método para la consolidación socio-integrativa/constructiva, deviene como forma de concretar lo disperso, o sea, la asignación de adscribir significados concretos allí 
donde el Derecho permanece indeterminado: el conflicto. Luego, la caracterización del conflicto como «intrascendencia» advierte que, en efecto, el conflicto, en la supresión de su trascendencia característica, adquiere, a su vez, una nueva importancia: la de ser constitutivo de una resolución oportuna donde el Derecho, sin permanecer silente, supone un babel de palabras y, por eso mismo, lo constituye. En este entendido, la condición teleológica de transformar el conflicto, apartándolo de su peculiaridad negativa, o sea, como evento a disgregar, ahora, se observa como positividad, es decir, oportunidad tendiente no a un hacer de la sociedad algo mejor, sino de apresarla a su antepasado determinador: el Homo Pacis que, sembrado en el pacifismo, ya es tendencia innata hacia la Cultura de Paz.

Esta afirmación supone que el conflicto es la derivación de una interpretación disidente, en uno u otro sentido, debido no a un deliberacionismo o un eje subjetivo calculador, sino, por el contrario, deviniente de la propia naturaleza de la regla jurídica, esto es, el carácter, eminentemente, abierto de la naturaleza lingüística que acompaña su composición -ya sea en el módelo continental europeo o el esquema angloparlante-, lo cual, presupone que, -pese a lo predicado por muchos -, las respuestas correctas en el Derecho no son posibles, mas si, las perspectivas diferenciales. La obviedad argumental de este factum, se constata, si logra advertirse que «en todos los campos de experiencia, no sólo en el de las reglas, hay un límite, inherente a la naturaleza del lenguaje, a la orientación que el lenguaje general puede proporcionar» (Hart, 1961, p. 157).

Así, el conflicto debe su trascendencia misma a la mediación -en extensión a los MASC todos- en tanto razón de ésta, empero, su intrascendencia se hace visible desde la vertiente gestante que no es él mismo, sino que, por simple pertenencia, deviene del elemento que lo concreta en la sociedad: el Derecho y su natural incertidumbre propiciada por la orientación de su construcción lingüística. De allí que, el conflicto sólo pueda ser analizado, desde su perfecta [in]trascendencia y no fuera de esta. Esta es la condición significativa que, hasta ahora ha dejado de lado, la teorética pospuesta a la consagración del conflicto como eje motor del todo social, pues, pasa por alto que la sociedad, jurídicamente, ordenada, pacífica -si acaso, se advierte, el modelo natural descriptivo de Locke- y legitimante del Derecho -si, por de pronto, Rosseau y Hobbes, pueden, en algun sentido, tener razón-, genera sus propios antagonismos presa de la inmanencia lingüística configurativa del Derecho, esto es, la asignación cambiante de significados y la multiplicidad de los mismos (Alexy, 1997, p. 24). Así, alguien puede, por ejemplo, dar su entendimiento, en un determinado contexto, a un derecho, que, bajo otra mirada, aparecerá, de inmediato, como obligación, suponerse una garantía, donde sólo hay deberes, todo lo cual, supone ya la existencia de un conflicto que -como se verá- sólo podrá ser resuelto en el acto generatriz de la interpretación (Alexy, 2002, pp. 96-97), esto es, la concreción creadora del Derecho en el nivel social: la mediación.

De esta forma, si, además, de conceder que el conflicto es una fuerza propulsora, una verdadera oportunidad, no, sin embargo, «un motor de cambio» (Lederach, 2009, p. 4), sino, la forma de redescubrirnos siendo agentes sociales tendientes a la integración por la fe impuesta en nuestra propia naturaleza, ese estado natural revelador del pacífismo interior que nos acompaña en tanto humanos, el mediador al transformar el conflicto, en esta nueva significación, implicada en la «[in] 


\section{I PEDAGOGIA NO AMBIENTE PENITENCIÁRIO: A EDUCAÇÃO QUE TRANSFORMA COM EDUCAÇÃO NO AMBIENTE PENITENCIÁRIO}

trascendencia» del conflcto mismo, el mediador, al transformar el conflicto, determina el Derecho mismo, concretándolo, y, por ende, crea Derecho interpretando en la indeterminación lo que es determinable: la metamorfosis del conflicto. Crea, a su vez, impetración a la justicia, en cierto sentido, activa, pues, no sólo se aplica a la transformación desde la indeterminación, sino que, en tanto comprometido socialmente, la diluye.

\section{CONCLUSIONES}

Superponer a la consideración, eminentemente, escéptica, referente a la imposibilidad de encontrar en el hombre valores o fundamentos que permitan tener una suerte de fe en sí mismo y en la propia naturaleza humana, es, presuponer, en efecto, la virtual condición de que la humanidad entera, en un sentido u otro, debe redescubrirse - $\mathrm{O}$, si se quiere, suponer una fe, que riñendo con lo que nuestra naturaleza evidencia, aun así se profesa y tiende a la consolidación de una humanidad adscrita al corazón del hombre-, lo cual, permite, a su vez, encontrar una forma de justificación ética del conjunto de reglas que denominamos: Derecho; empero, ver, además, en este justificante, una razón del Derecho mismo, no cifrada en la instrumentalización del ser humano para la sobrevivencia de una sociedad indiferente, al contrario, observar que, siendo el humano constructor de su propio contorno y, eminentemente, comprometido en su propia sociedad, el Derecho tiene como función proteger el estado natural que le dio forma y recordar, constantemente, al ser humano que hay algo en él digno de protegerse: el innato constituirse en Homo Pacis y hacer del pacifismo la forma para integrar a la sociedad como un todo en el cual el principium unus pro omnibus, omnes pro uno no es una tendencia, sino una verdad comunitaria.

$\mathrm{Si}$, en efecto, existe una relación mediación/Derecho, en tanto, la primera constituir como fuerza virtual para la transformación del conflicto y, por su parte, la segunda, evidenciarse como fuente para la protección de un estado natural presupuesto, en el cual, el humano se constituye en agente de paz dada su propia condición, entonces, surge, como una característica añadida a las consideraciones del conflicto actuales, la condición de la [in]trascendencia del conflicto mismo que expresa, por sí misma, la consideración del conflcto devenido como efecto de la indeterminación del Derecho, constituida por la construcción lingüística que este expone, empero, que no relega el carácter trascendente mismo del antagonismo, sino que, evidenciando, en el Derecho cierta incertidumbre, asigna a la transformación propia del conflicto, una forma de concretar las reglas jurídicas cuando estas se encuentran indeterminadas en un caso concreto. Así el mediador, en un sentido especial y sin romper con su propia «neutralidad», al diluir el conflicto propiciado por la propia indeterminación del derecho, lo determina.

Solo en este sentido, puede, entenderse el conflicto como esquema constructivo y la ciudadanización de la justicia como potencia que, involucrando a la sociedad en el desvanecimiento de sus propios antagonismos, concreta el Derecho desde su irresolución. En ese sentido, puede afirmarse que, con nuestras interpelaciones conflictivas evidenciamos un Derecho vacilante, empero, procedemos a concretarlo creando una solución dispuesta en la transformación del conflicto mismo que, en cuanto tal, implica una nueva forma de ver la realidad interrelacional social y una nueva 
forma de concebir el Derecho ya presuntamente regulado. Finalmente, esto permite asignar, a nuestra condición humana una trascendencia única: somos justificadores éticos del Derecho, no como meros destinatarios de sus reglas, por el contrario, razón de su persistencia.

\section{REFERENCIAS}

Alchourrón, C., \& Buligin, E. (1997). Sobre la Existencia de las Normas Jurídicas. México D. F., México: Fontamara.

Alexy, R. (2006). Derecho y Razón Práctica. México D. F., México: Fontamara.

Alexy, R. (2002). Teoría de los Derechos Fundamentales. (E. Garzón, Trad.) Madrid, españa: Centro de Estudios Políticos y Constitucionales.

Alexy, R. (1997). Teoría de la Argumentación Jurídica. La teoría del discurso racional como teoría de la fundamención jurídica. (M. Atienza, \& I. Espejo, Trads.) Madrid, España: Centro de Estudios Políticos y Constitucionales .

Atienza, M. (2009). El Sentido del Derecho. Barcelona, España: Ariel.

Austin, J. (1995). The Province of Jurisprudence Determined. Cambridge, UK: Cambridge University Press.

Beling, E. (2002). Esquema de Derecho Penal. La Doctrina del Delito - Tipo. (S. Soler, Trad.) Buenos Aires, Argentina: El Foro. Bruno, G. (1981). Sobre el Infinito Universo y los Mundos. (A. Cappelletti, Trad.) Buenos Aires, Argentina: Orbis.

Cabello, P. (Enero de 2016). "Lauream Pacis”: Una Cultura de Paz a través del deporte. Comunitania, 141-155.

Dumas, A. (2008). The three musketeers. (R. Pevear, Trad.) Westminster, United Kingdom: Penguin Classics.

Dworkin, R. (2008). La Democracia Posible. Principios para un nuevo debate politico. (E. Weikert, Trad.) Barcelona, España: Paidós.

Dworkin, R. (2005). El Imperio de la Justicia. (C. Ferrari, Trad.) Barcelona, España: Gedisa.

Finnis, J. (1992). Ley Naturaly Derechos Naturales. (C. Orrego, Trad.) Buenos Aires, Argentina: Abeledo-Perrot.

Fisas, V. (Mayo de 2011). Educar para una Cultura de Paz. Quaderns de Construccio de Pau , 2-8.

Frank, J. (2001). Derecho e Incertidumbre (Tercera ed.). (Fontamara, Ed., \& C. Bidegain, Trad.) México D. F., México: Biblioteca de Ética, Filosofía del Derecho y Política.

Galtung, J. (1998). Tras la Violencia, 3R: Reconstrucción, Reconciliación, Resolución. Afrontando los efectos visibles e invisibles de la guerra y la violencia. Gobierno Vasco, España: Bakeaz.

Gorjón, F. (2016). Mediación, ciencia social emergente. Comunitania (12), 9-25.

Gorjón, F., \& Sánchez, A. (2015). Las 101 Preguntas de la Mediación. Guia práctica para el abogado. México D. F., México: Tirant lo Blanch .

Gorjón, F. (2015). Teoría de la Impetración de la Justicia. Por la necesaria ciudadanización de la justicia y de la paz. Comunitania (10), 113-131.

Gorjón, F., \& Sáenz, K. (2013). Los Intangibles de la Mediación. En F. Gorjón, \& A. López, Estado del Arte de la Mediación (págs. 125-146). Pamplona, España: Aranzadi.

Gorjón, G., \& Sauseda, B. (2018). Justicia Restaurativa, una herramienta de paz en la resolución de conflictos comunitarios. Caso Nuevo León. Política Criminal, 13 (25), 548-571.

Gorjón, F., \& Steele, J. (2008). Métodos Alternativos de Solución de Conflictos. México D. F., México: Oxford University Press.

Hart, H. (1961). El Concepto de Derecho. (G. R. Carrió, Trad.) Buenos Aires, Argentina: Abeledo-Perrot. 


\section{I PEDAGOGIA NO AMBIENTE PENITENCIÁRIO: A EDUCAÇÃO QUE TRANSFORMA COM EDUCAÇÃO NO AMBIENTE PENITENCIÁRIO}

Hobbes, T. (1980). El Leviatán. (A. Escohotado, Trad.) Madrid, España: Nacional.

Kelsen, H. (2007). Teoría Pura del Derecho. (R. J. Vernengo, Trad.) México D. F., México: Porrúa.

Lederach, J. (2009). El Pequeño Libro de Transformación de Conflictos. Bogotá D. C., Colombia: Good Books .

Leroy, G., Padilla, M., Munguía, C., Burgos, J., \& Morando, A. (2009). Análisis de los Efectos de la Elaboración de Enunciados Contrafácticos en una Tarea de Elección. Universitas Psychologica, 8 (2), 385-397.

Locke, J. (2009). Carta sobre la Tolerancia. México D. F., México: La Guillotina.

Locke, J. (2005). Segundo Tratado sobre el Gobierno Civil. Un ensayo concerniente al verdadero origen, alcance y finalidad del Gobierno Civil. (C. Amor, \& P. Staffori, Trads.) Buenos Aires, Argentina: Universidad Nacional de Quilmes.

Locke, J. (1999). Ensayo sobre el Entendimiento Humano (Segunda ed.). (E. O’Gorman, Trad.) México D. F., México: Fondo de Cultura Económica.

Maquiavelo, N. (2002). El Príncipe. (F. Alcántara, Trad.) Venezuela: Planeta S. A.

Muñoz, F., \& Molina, B. (2010). Una Cultura de Paz Compleja y Conflictiva. La búsqueda de equilibrios dinámicos. Revista Pazy Conflictos (3), 44-61.

Pascal, B. (1999). Pensamientos. Barcelona, España: Folio.

Peces-Barba, G. (2000). Ética, Poder y Derecho. Reflexiones ante el fin de siglo. México D. F., México: Fontamara.

Rawls, J. (2002). La Justicia como Equidad. Una reformulación. (A. De Francisco, Trad.) Barcelona, españa: Paidós.

Rawls, J. (1995). Teoría de la Justicia (Segunda ed.). (M. González, Trad.) México D. F., México: Fondo de Cultura Económica.

Raz, J. (1985). La Autoridad del Derecho. Ensayos sobre Derecho y Moral (Segunda ed.). (R. Tamayo, Trad.) México D. F., México: Universidad Nacional Autónoma de México.

Redorta, J. (2011). Gestión de Conflictos. Lo que necesita saber. Barcelona, España: UOC.

Ross, A. (2008). El Concepto de Validez y el Conflicto entre el Positivismo Jurídico y el Derecho Natural. Academia (12), 199-220.

Rousseau, J. (1983). El Contrato Social. (E. Azcoaga, Trad.) Madrid, España: Sarpe

Wilde, O. (1986). La Decadencia de la Mentira. En O. Wilde, Ensayos-Artículos (J. Gómez, Trad., págs. 101-142). Barcelona, España: Hyspamérica. 